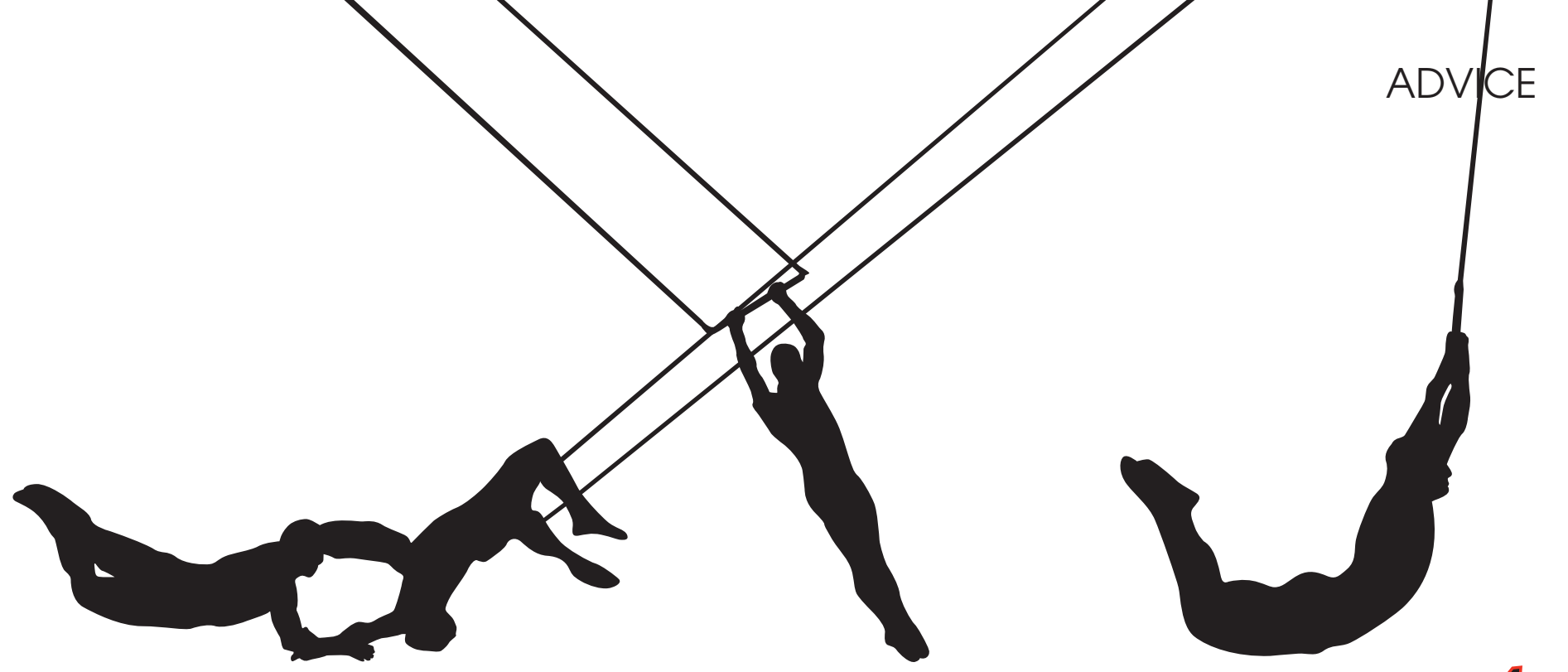

\title{
PERFORMING AT
}
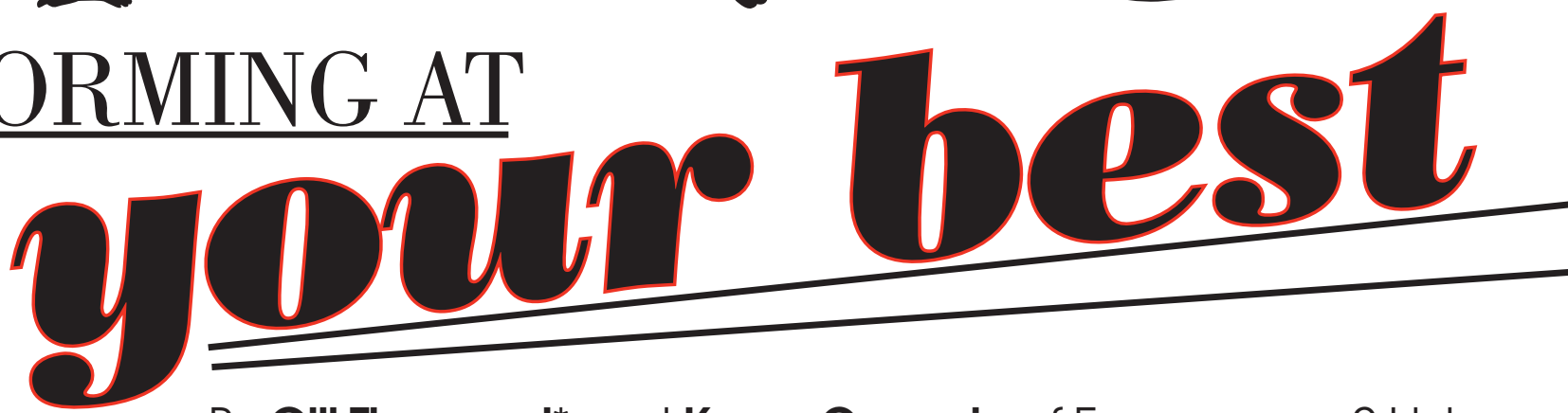

By Gill Thurgood* and Karen Crampin of Empowerme2 Ltd.

* Gill qualified as a dental auxiliary in 1967 at New Cross and worked as an aux/ therapist in Northamptonshire and Essex before working in oral health promotion in Enfield, Haringey and Essex. She taught dental nurses for ten years at Epping Forest College. In 1998 she moved to a major pharmaceutical company to promote employee wellbeing. After ten years she decided to set up Empowerme2 with a colleague and associates. According to Gill, 'dentistry is still close to my heart which is why I am still a registered dental therapist!'
How do you perform?

Many people go through life without addressing how they feel or if they could feel or perform better. We all have to perform to varying degrees and are measured on our performance whether it's at work, at home or on the golf course. How do you perform as an employee, a parent, a friend, a member of your community? What makes a great performance?

Many researchers have identified energy to be the key to maintaining high performance in all areas of life. In physics energy is defined as the capacity to work - the question is how do you build your energy capacity and how do you manage it?

\section{Managing energy}

Managing your energy is the key to achieving high performance, health, happiness and life balance: there are a limited number of hours in the day, but there is no limit on the amount of energy we can apply. Take a moment to consider your energy level over the past week. Where are you on a scale of 1 to 10 , where 1 is exhausted and unable to get out of bed and 10 is full of beans and raring to go? What would it take to increase your score by just 1 point? Below are some pointers to help you.

- Energy is derived from three main sources

- body, mind and spirit. In order to be fully engaged and perform at our best, we need to be energised in all three areas

- Physical energy from the body allows us to

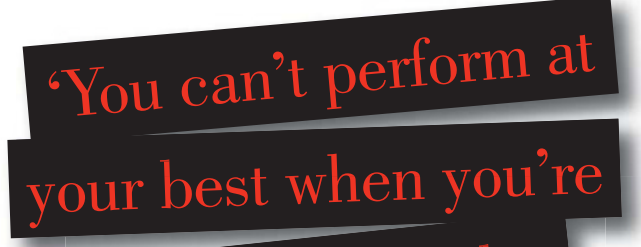

hungry, or, at the

other extreme, in

\section{a food coma!}

do all the activities we want to in life; it is derived from food, drink, sleep and physical activity

- Emotional and mental energy stems from the mind, giving us motivation, hope and focus. Emotional energy is associated with the feelings of enthusiasm, optimism and confidence and mental energy with logical thinking, focus and decision making

- Energy from the spirit provides meaning and purpose and is associated with our persistence, determination, fulfillment and passion.

\section{Improving energy levels}

Underpinning all energy management is the physical aspect. Here are some suggestions to help you improve your energy levels through nutrition, exercise and sleep. 
